\title{
Resposta à Demanda na Energia Elétrica Residencial por Controle Direto das Cargas
}

\author{
Thamires Faleiro Martins ${ }^{1}$, Mirlane Pereira Silva ${ }^{1}$, Fabiano João Leoncio de \\ Padua $^{1}$ \\ ${ }^{1}$ Departamento de Eletroeletrônica - Campus Cuiabá - \\ Instituto Federal de Educação, Ciência e Tecnologia de Mato Grosso (IFMT) - \\ Cuiabá, MT - Brazil \\ \{thamires.faleiro.martins, mirlanepereirasilva8\}@gmail.com, \\ fabiano.padua@cba.ifmt.edu.br
}

\begin{abstract}
This paper proposes a demand side management system of residential electricity consumption through direct control by the utility using low cost devices. Through three levels of need (common, worrying and urgent) the controllable loads will be turned off in a list from lowest to highest priority. The expected result is a reduction in peak residential consumption values without loss of quality of life, as well as a partial shutdown of residential consumption.
\end{abstract}

Resumo. Este trabalho traz uma proposta de um sistema de gerenciamento pelo lado da demanda do consumo de energia elétrica residencial, através do controle direto pela concessionária utilizando dispositivos de baixo custo. Através de três níveis de necessidade (comum, preocupante e urgente) as cargas controláveis serão desligadas em uma lista da menor para a maior prioridade. $O$ resultado esperado é uma redução nos valores de pico de consumo residencial sem perda de qualidade de vida, bem como o desligamento parcial do consumo residencial.

\section{Gerenciamento de Energia Elétrica pelo Lado da Demanda}

Com as redes elétricas inteligentes é possível ter um moderno sistema de gerenciamento de eletricidade utilizando sensores, automação, telecomunicação e sistemas integrados visando melhorias dos sistemas elétricos, tanto em nível de eficiência bem como da segurança do sistema (BERGER, 2015). Com esta desta tecnologia de gerenciamento do consumo têm-se uma diminuição de perdas, aumento do desempenho e economia financeira. Desta forma, contribui fundamentalmente para uma utilização mais eficiente da energia elétrica.

O Gerenciamento pelo Lado da Demanda (DSM) foi concebido como o planejamento, implementação e monitoramento de atividades que visam influenciar o uso da eletricidade de maneira que produza mudanças desejadas na curva de carga da concessionária de energia elétrica (CAVALCA, 2018). O termo DSM agrupa um conjunto de conceitos e agregando diversas ações para o gerenciamento de carga, as quais inclui, por exemplo, o programa de Respostas à Demanda (DR- Demand Response) (CAVALCA, 2018). 
Para Camargo e Teive (2006) a DR pode se dar através do Controle Direto da Carga (DLC), através de acionamentos e desligamentos de carga ou por meio indireto através da tarifação horária que atua como meio indutor e modulador da curva de carga, haja vista que o consumidor evitará o consumo no horário de ponta com objetivo de reduzir sua fatura de energia elétrica.

\section{Controle de Carga pela Concessionária}

Foi estabelecido que o medidor de energia elétrica residencial tenha três relés para que toda carga elétrica residencial seja distribuída neles e uma interface de comunicação. A prioridade que cada relé possui é: (1) urgente; (2) preocupante; e (3) comum. O consumidor que deverá definir as cargas que serão ligadas em cada relé.

Considera-se que há uma rede de comunicação interligando os medidores de energia elétrica dos consumidores com um servidor localizado na concessionária. $\mathrm{O}$ servidor gerencia os medidores de energia elétrica de cada consumidor. A somatória do consumo total dos consumidores é comparada com a carga disponível à concessionária vinda de uma ou mais geração de energia elétrica. Caso haja geração o suficiente para atender todos consumidores nada acontece no sistema, considera-se o nível 0. Porém, caso não tenha geração o suficiente o servidor faz uma análise da diferença de carga e atua no corte de carga seguindo três níveis 1,2 e 3.

\section{Resultados}

Foi desenvolvido um protótipo, visto na Figura 1, utilizando um computador como servidor da concessionária e três microcontroladores como medidores de energia elétrica. É considerado que exista uma nuvem para comunicação, onde neste trabalho utilizou a tecnologia sem fio Wi-Fi.

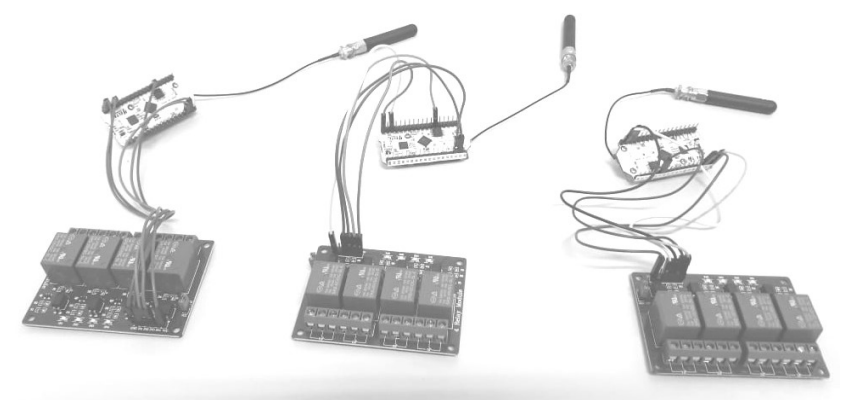

Figura 1. Protótipo desenvolvido em laboratório

Através da utilização da ferramenta computacional Load Profile Generator (LPG, 2019) para a modelagem foi possível obter um perfil de consumo simulado de uma residência simples. Esse perfil de consumo equivale a um dia (24 horas) e foi colocado em cada microcontrolador. No servidor foi desenvolvido um algoritmo que gera uma demanda de forma aleatória, do tipo Gaussiana, equivalente a um dia.

A Figura 2 mostra um gráfico com o perfil de consumo residencial (energia consumida) e o perfil de demanda da concessionária (energia gerada). Pode-se observar que o servidor desligará os relés de cada residência conforme o nível que a energia consumida ultrapassa a energia gerada. Tem-se um sistema que permite manter o consumo de 
energia elétrica dentro do limite da capacidade de energia gerada. Desta maneira pode-se controlar blackouts no sistema, permitindo que pelo menos os consumidores tenham uma parte da residência energizada. Em adição, extraindo a quantidade de vezes que os relés são acionados ou não durante um dia, é possível apresentar graficamente na Figura 2.
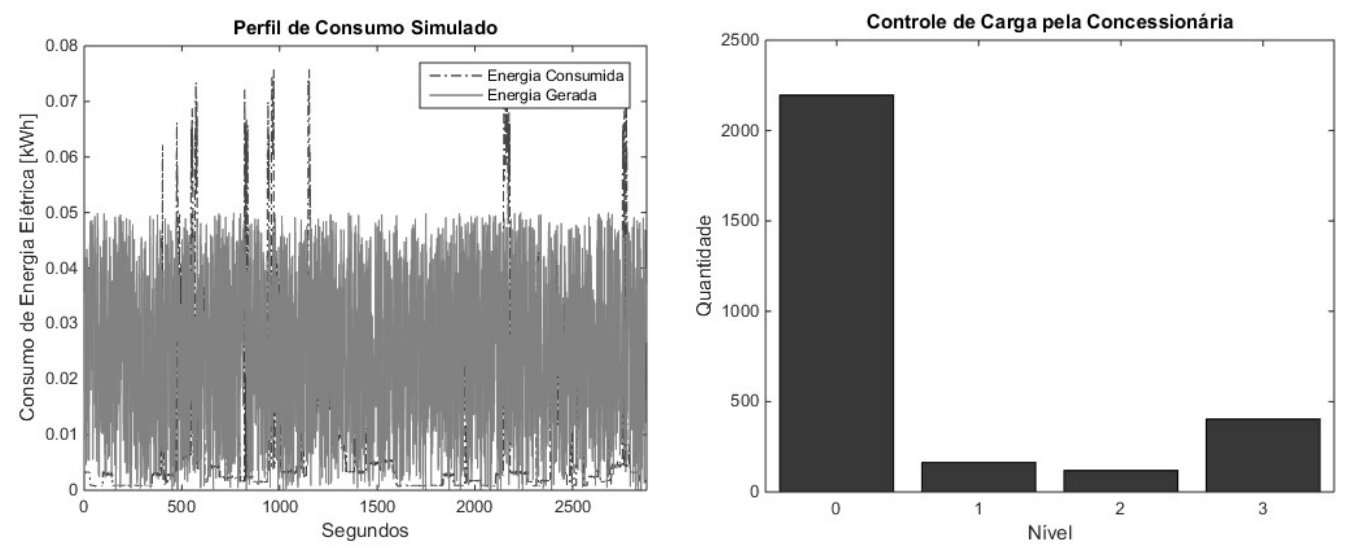

Figura 2. Simulação da energia gerada e consumida

\section{Conclusão}

A implementação de GLD com um sistema automático de controle e supervisão possibilita a adequação da demanda a padrões de consumo que beneficiem a eficiência do sistema.

A partir dos resultados obtidos foi possível notar a possibilidade de controlar o consumo de carga residencial sem a necessidade de um corte de energia geral.

Dentro desse contexto, o presente trabalho apresentou uma solução de controle de carga residencial através da concessionária de energia elétrica simulada em uma bancada com protótipos.

\section{Agradecimento}

Agradecimento pelo apoio financeiro e bolsa de iniciação científica através do programa institucional PIBIC-EM/CNPq.

\section{Referências}

Berger, Lars Torsten; Iniewski, Krzysztof (2015) "Redes Elétricas Inteligentes Aplicações, Comunicação e Segurança", LTC.

Camargo, Cornélio C. de Brasil; Teive, Raimundo C. Ghizoni. (2006) "Gerenciamento pelo lado da demanda: Aspectos técnicos, econômicos, ambientais e políticas de conservação de energia", Univali, p.287.

Cavalca, Diego Luiz (2018) “Algoritmo Híbrido de Otimização por Enxame de Partículas Aplicado ao Gerenciamento de Cargas Residenciais”, Dissertação de Mestrado em Ciências da Computação, UFSCar.

LPG (2019) "Load Profile Generator", Disponível em: $<$ https://www.loadprofilegenerator.de/>, Acesso em 01-07-2019. 